\title{
Validating the National Survey of Student Engagement (NSSE) at a Research-Intensive University
}

\author{
Chosang Tendhar ${ }^{1}$, Steven M. Culver ${ }^{2}$ \& Penny L. Burge ${ }^{1}$ \\ ${ }^{1}$ Educational Research \& Evaluation, School of Education, Virginia Tech, Blacksburg, VA, USA \\ ${ }^{2}$ Office of Assessment and Evaluation, Virginia Tech, VA, USA \\ Correspondence: Steven M. Culver, Office of Assessment and Evaluation, 122 Hillcrest Hall (0157), Virginia \\ Tech, Blacksburg, VA 24061, USA. Tel: 1-540-231-4581. E-mail: sculver@vt.edu
}

Received: February 18, 2013 Accepted: March 4, 2013 Available online: March 19, 2013

doi:10.11114/jets.v1i1.70

URL: http://dx.doi.org/10.11114/jets.v1i1.70

\begin{abstract}
The National Survey of Student Engagement (NSSE) has been used at universities across the U.S. and Canada to gather information about the quality of engagement of first-year students and graduating students. Institutions use NSSE's five benchmarks of effective educational practice to compare themselves with other schools and to focus in on ways to improve the educational experiences of their students. However, studies indicate that these benchmarks may not be a valid way to convey NSSE information. This study was conducted to investigate whether or not NSSE's five-factor model is the best fit for student engagement data collected at a large, public, research-intensive, land-grant university. The five-factor model did not fit the data for the 2008 sample of senior students at this university. Rather, a revised model using six factors instead of five and 21 of 42 items provided a more valid test blueprint. This new model was then tested and found to fit the 2011 sample of senior students at the same university. Discussion regarding use of a nationally collected data at an individual institution is provided.
\end{abstract}

Keywords: National Survey of Student Engagement (NSSE), exploratory factor analysis(EFA), confirmatory factor analysis (CFA), student engagement

\section{Introduction}

Ever since Astin (1984) proposed a developmental model of college student learning that emphasized the concept of involvement, educators in higher education around the globe have become more focused on developing what has come to be known as "student engagement." Through the curriculum, faculty have developed "learning communities," service learning opportunities, internships, and global exchanges as ways to augment "the amount of physical and psychological energy" (Astin, 1984, p. 297) students devote to their academic experiences. In addition, universities have developed co-curricular activities intended to increase students' interactions with peers and others associated with the university community. Increases in student engagement have been shown to be positively linked to individual satisfaction, personal growth, and the overall success of students (Astin, 1993; Bruffee, 1993; Goodsell, Maher, \& Tinto, 1992; McKeachie, Pintrich, Lin, \& Smith, 1986; Pascarella \& Terenzini, 1991).

Broadly defined, student engagement is related to student motivation and commitment to learning, a sense of belonging, and development of relationships with adults, peers, and others who support their learning and accomplishments (Jones, 2009). More specifically, it is the "time and energy students devote to educationally sound activities inside and outside of the classroom" (Kuh, 2003, p. 25). Students who are more engaged are more likely to be academically successful (Pascarella \&Terenzini, 2005; Tinto, 1997), more likely to graduate, receive better grades, and be more satisfied with their collegiate experience (Astin \& Sax, 1998; Kuh, Kinzie, Schuh, Whitt, \& Associates, 2005).

Since 2000, the most often used instrument to measure higher education students' perceptions of engagement is the National Survey of Student Engagement (NSSE). The NSSE was specifically created to examine the degree to which students engage in meaningful educational practices that are significantly related to students' positive outcomes (Kuh, 2003). It is administered every spring semester to first-year students and seniors at colleges and universities in the U.S. and Canada. Students from almost 1,500 different baccalaureate-granting institutions 
have taken the NSSE. In 2011 alone, almost two million first-year and senior students from 751 colleges and universities were invited to participate in the NSSE administration (NSSE, 2011).

NSSE provides summative information on five scales that can be used as benchmarks to compare institutions to institutions or cohorts within institutions. More and more schools have become involved with the NSSE and in comparing themselves with other universities on these scales (Lutz \& Culver, 2010). The results have also been reported as part of the college ranking processes in magazines and newspapers, such as USA Today, and in centralized information websites, such as the College Portrait (http://www.collegeportraits.org/), sponsored by the Voluntary System of Accountability. Given the high profile nature of this reporting, the results of comparisons on the five benchmark scales of the NSSE have raised the stakes of this type of assessment.

Though Kuh (2009) emphasizes that the NSSE project was intended to "provide high-quality, actionable data that institutions can use to improve the undergraduate experience" (p. 9), there have been questions raised about how well those data capture the perceived experiences of students at a particular university. For example, Swerdzewski, Miller, and Mitchell (2007) collected evidence to determine whether or not NSSE information could be used to make "programmatic and policy changes" (p. 9) at James Madison University (VA). Their results indicated that a confirmatory factor analysis of the benchmarks specified by the NSSE literature produced poor model fit. Their conclusion was that a comparison of benchmark scores from their sample of students to scores from a sample at another university should not be made. They further noted that policy or programmatic decisions should not be made at that particular university based on the benchmark scores.

In a similar study, Lutz and Culver (2010) analyzed the data from a large land-grant university in the southeastern U.S. Using confirmatory factor analyses (CFA) on data from all students at the institution and then on data from first-year and seniors, respectively, they found that none of the indices used, such as Chi-Square, Comparative Fit Index (CFI), Tucker Louis Index (TLI), Root Mean Square Error of Approximation (RMSEA), and Standardized Root Mean Square Residual (SRMR) supported the model for any of the groups at that particular university. As with Swerdzewski, Miller, and Mitchell (2007), they concluded that assessment practitioners should be cautious in their use of NSSE data at their institution.

In yet another validation study conducted by LaNasa, Cabrera, and Trangsrud (2009) on only the first-year cohort at their institution, the five-factor NSSE model failed to fit the data collected from their first-year student cohort. On further analyses, they found that an eight factor model provided a better fit to their data. Similar results obtained by Campbell and Cabrera (2011) at a research-intensive university led them to conclude that carefully examining the reliability and validity of the NSSE benchmarks at the institutional level is needed before any school uses the data collected.

In his effort to provide valid data from the instrument, Pike (2006) made a strong case for using 12 NSSE scale lets, rather than the five benchmarks. His justification for developing scale lets was that they help overcome difficulties in disaggregating survey data at the college or department level. In addition, they allow decision makers at the institution and system level to gauge experiences of institution-specific student engagement, and they assist in detecting areas that need rectification. Furthermore, scale let scores provided greater explanatory power than the five NSSE benchmark scale scores.

In summary, there are questions about the validity of the five benchmark subscale scores obtained from the NSSE. Furthermore, these scores have been presented as applicable to all types of institutions, regardless of mission, location, or type of student served. However, previous research has indicated that levels of engagement, and types of engagement, may vary by such institutional factors, not to mention personal characteristics of the student. For instance, Pike, Kuh, and Gonyea (2003) found that students attending different types and sizes of colleges and universities reported having different patterns of experience in college. Characteristics of schools also play a factor. For instance, colleges with larger percentages of students living on-campus tend to have higher levels of engagement (Pike \& Kuh, 2005). Smart, Feldman, and Ethington (2000) have also suggested that disciplinary area may also be related to student engagement. In addition, Harper (2009) has suggested that racial minorities engage differently with their college environments, making measurement of this engagement more complex.

\section{Purpose of the Study}

The purpose of this study was to examine whether the five NSSE benchmark scales provided valid information for use at our particular institution. Such an examination is necessary because of the concerns as noted in the literature. Other studies have been conducted at research-intensive universities (e.g., Campbell \&Cabrera, 2011; LaNasa, Cabrera, \& Trangsrud, 2009), but both of these were urban institutions with different missions than our public, land-grant institution. Though the items making up the NSSE have strong theoretical grounding, there are 
questions regarding the construct validity of the five NSSE benchmarks. In addition, good assessment practice suggests caution in using institution-specific reports derived from a national survey such as NSSE without ensuring their validity on the local level (Yarbrough, Shulha, Hopson, \& Caruthers, 2011). Specifically, we seek to answer three research questions related to the construct validity of the NSSE five-benchmark model using the student data from seniors at our institution. Our focus was on the senior cohort only because of their longer periods of time spent at our institution.

1. Using the 2008 senior cohort sample, are there five separate, stable benchmarks that measure engagement at our institution?

2. If these five benchmarks do not provide a valid model of engagement with this sample, is there another model that provides a better fit for the data?

3. Using the best model, either the NSSE five-benchmark or the better-fit model, can we provide a valid measure of student engagement for the 2011 senior cohort sample at this institution?

\section{Methods}

\subsection{Samples}

Sample 1. The NSSE data used to answer research questions \#1 and \#2 were collected in the spring of 2008. A total of 757 seniors at Virginia Tech responded to the web-based version of the NSSE instrument, yielding a response rate of $39 \%$. However, after those with missing data were removed, the sample was 679 . Of these, 56\% were male students; $44 \%$ female. In terms of race, $6.6 \%$ were Asian, Asian American or Pacific Islander; $2.5 \%$ were African American; 81.3\% were White (non-Hispanic), and 9.6\% indicated "other." Further, 3.5\% identified as international students.

Sample 2. The NSSE data used to answer research question \#3 were collected in the spring of 2011. A total of 756 seniors responded to the web-based NSSE instrument, yielding a response rate of $17 \%$. However, after those with missing data were removed, the sample was 655 . Of these, $49.2 \%$ were male; $50.8 \%$ were female. Asian, Asian American, or Pacific Islanders constituted 6.9\% of the sample; $2.4 \%$ were African American; $82.4 \%$ were White (non-Hispanic), and $8.3 \%$ indicated "other." International students constituted $2.7 \%$ of the sample.

\subsection{Instrument}

The NSSE's development began with the Pew Foundation's effort to bring together a panel of experts to develop a survey to measure student engagement under the accepted theory that more engagement means more learning (see Chickering \& Gamson, 1987; NSSE, 2008). The NSSE instrument collects information in five categories. First, students are asked about their participation in "dozens of educationally purposeful activities" (Kuh, 2009), such as interacting with faculty and with peers, the amount of time they spend studying or in other activities. A second set of questions asks about the amount of reading and writing they do, as well as questions about their coursework and examinations. A third set of questions asks students about their college environment, whether they feel supported and the quality of their interactions with others (peers, faculty, and administrators) on campus. A fourth grouping of questions asks students for their background information, such as age, gender, race/ethnicity, and major field of study. A fifth set of questions asks students to estimate their educational and personal growth since beginning college in such areas as written and oral communication, ethical development, and vocational preparation.

Five benchmarks were created from 42 key items on the NSSE survey using a combination of engagement and educational impact theory and exploratory factor analysis (Pike, Kuh, McCormick, Ethington, \& Smart, 2011). The five benchmarks were designed to tap into five different, though inter-related constructs of student engagement with their institution and to be applicable to any institutional setting, regardless of size, mission, or students served (Campbell \& Cabrera, 2011). These benchmarks, labeled the Benchmarks of Effective Educational Practice, are

- Level of Academic Challenge (LAC)

- $\quad$ Active and Collaborative Learning (ACL)

- $\quad$ Enriching Educational Experiences (EEE)

- $\quad$ Student-Faculty Interaction (SFI)

- $\quad$ Supportive Campus Environment (SCE)

The Level of Academic Challenge (LAC) was measured by 11 items, such as a number of assigned textbooks, number of written papers or reports, emphasis of coursework (analysis, synthesis, making of judgments, 
application), and whether the campus environment supports spending significant amounts of time on academic work. Active and Collaborative Learning (ACL) was measured by seven items, such as how often students asked questions in class, made a class presentation, worked with classmates outside of class, or participated in a community-based project as part of a class. Enriching Educational Experiences (EEE) was measured by 12 items, such as participation in co-curricular activities, internships, community service, foreign language coursework, or learning communities. Student-Faculty Interactions (SFI) was measured by six items, such as how often students discussed grades or assignments with an instructor, talked about career plans with a faculty member, or worked with faculty members on activities or research outside of class. Finally, the Supportive Campus Environment (SCE) was measured by six items, such as quality of relationships with faculty members, other students, administrative personnel, and whether the campus environment provides support for thriving socially.

\subsection{Model Testing}

Using the data from the 2008 senior sample, we tested a confirmatory factor model with the NSSE's five benchmark scales as each of the factors using Maximum Likelihood (ML) methods in Mplus version 5.1 (Muthen \& Muthen, 2008). There are many measures for fit, but we relied on three robust measures of fit to judge the CFA model: the Comparative Fix Index (CFI), the Tucker-Lewis Index (TLI), and the Root Mean Square Error of Approximation (RMSEA). Guided by recommendations from the literature (Hu \& Bentler, 1999; $\mathrm{Yu}, 2002$ ), we sought CFI and TLI values of 0.95 or higher to indicate an appropriate level of fit. In regard to RMSEA values (see Brown, 2006; Hu \& Bentler, 1999), we considered values less than .06 to be suitable. Close fit (CFit) indicates the probability (p) that the RMSEA is less than or equal to 0.05 (see Brown, 2006). We also report the Standardized Root Mean Square Residual (SRMR), with a value of .08 or less indicated an acceptable model (Hu \& Bentler, 1999).

After the NSSE five-benchmark structure did not provide a good fit for the student engagement data at our institution, we then employed exploratory factor analysis (EFA), using promax rotation, to identify a factor structure that might provide a better fit for the 2008 senior data from our university. This new model was then tested, using confirmatory factor analysis on the data from the 2011 senior sample group at the same institution.

\section{Results}

\subsection{Confirmatory Factor Analysis Results for NSSE Five-factor Model}

The results of the confirmatory factor analysis of the NSSE five-factor model indicated that the model was not a good fit for the 2008 senior data at our institution. Table 1presents the reliability information of the original instrument and its five factors, as well as the factor loadings for each of the 42 items. As shown, the overall reliability was .869 . Though Cronbach's alpha of each of the five factors (LAC, ACL, SFI, EEE, and SCE) ranged between .616 and .772, many of the items did not load well on the predicted factor. For example, of the 11 items predicted to load on Level of Academic Engagement, 5 of them had loadings below . 3 and two more had loadings above .3 but less than .5. Similarly, of the 12 items predicted to load on Enriching Educational Experiences, nine had loadings below .3. The only factor to have all predicted items load above .5 was Supportive Campus Environment.

Table 1. Benchmarks and Item loadings for the NSSE Five-Benchmark Model With the 2008 Senior Sample $(\mathrm{n}=679)$

Benchmark Measure Loading Benchmark Reliability

$\begin{array}{ll}\text { READASGN } & .247 \\ \text { WRITEMOR } & .295 \\ \text { WRITEMID } & .318 \\ \text { WRITESML } & .218 \\ \text { ANALYZE } & .705 \\ \text { SYNTHESZ } & .725\end{array}$




$\begin{array}{ll}\text { EVALUATE } & .706 \\ \text { APPLYING } & .688 \\ \text { WORKHARD } & .450 \\ \text { ACADPR01 } & .273 \\ \text { ENVSCHOL } & .292\end{array}$

Active and Collaborative Learning

$\begin{array}{ll}\text { CLQUEST } & .558 \\ \text { CLPRESEN } & .477 \\ \text { CLASSGRP } & .312 \\ \text { OCCGRP } & .385 \\ \text { TUTOR } & .437 \\ \text { COMMPROJ } & .469 \\ \text { OOCIDEAS } & .603\end{array}$

Student-Faculty Interaction

$\begin{array}{ll}\text { FACGRADE } & .580 \\ \text { FACPLANS } & .709 \\ \text { FACIDEAS } & .735 \\ \text { FACFEED } & .502 \\ \text { FACOTHER } & .649 \\ \text { RESRCH04 } & .314\end{array}$

Enriching Educational Experiences

DIVRSTUD

DIFFSTU2

.830

.842

ENVDIVRS

.236

COCURR01

.194

ITACADEM

.301

INTERN04

.138

VOLNTR04

.231

LRNCOM04

.259

FORLNG04

.134

STDABR04

.185

INDSTD04

.112

SNRX04

.158

Supportive Campus Environment

ENVSOCAL

.603

.612

.638

ENVACAD

.511

ENVSTU

.724

ENVFAC

.628

Note: Refer to the College Student Report NSSE 2008 and 2011 Codebook for the actual questions (www.nsse.iub.edu/). 
The fit indices presented in Table 2 further demonstrate that the NSSE five-factor model does not provide an adequate fit for the 2008 data collected from seniors at our institution. For example, the CFI is below our .95 threshold and the RMSEA is above .06, with the Close fit (CFit) indicating a probability of zero that RMSEA is less than or equal to 0.05 (see Brown, 2006).

Table 2. Fit Indices of the NSSE Five-Benchmark Model With the 2008 Senior Sample

\begin{tabular}{cccccc}
\hline Cohort & CFI & TLI & RMSEA & CFit & SRMR \\
\hline Seniors & .663 & .641 & .068 & 0 & .077 \\
\hline
\end{tabular}

\subsection{Results of Exploratory Factor Analysis}

Given the results of our CFA and the failure of the NSSE five-factor model to fit our data, we then used exploratory factor analysis (EFA) to explore the factor structure that would emerge from the data. Using principal components analysis and retaining factors of eigenvalues greater than 1, the initial results revealed 11 potential factors after promax rotation. Item loadings on the factors were then examined and items with cross-loadings on factors were eliminated from the analyses. For the purposes of our study, items were retained if their primary factor loading was at least .50 with no cross-loading of .30 or above. Through this process, 21 items were removed, and the principal components factor analysis using promax rotation was run on the remaining 21 items. This analysis resulted in six factors, explaining $61.89 \%$ of the variance. These factors we have labeled(1) student-faculty interaction (SFI), with six items and a Cronbach's reliability of .751;(2) higher-order thinking skill (HOTS), with four items and a reliability of .817;(3) supportive campus environment (SCE), with four items and a reliability of .795;(4) quality of relationship (QoR), with three items and a reliability of .705;(5) writing challenge (WC), with three items and reliability of .661;(6) diversity (D), with two items and a reliability of .850 .

Table 3. Factor Loadings for Exploratory Factor Analysis With Promax Rotation of the Revised NSSE Model

With the 2008 Senior Sample $(n=679)$

\begin{tabular}{|c|c|c|c|c|c|c|}
\hline & \multirow[b]{2}{*}{ SFI } & \multirow[b]{2}{*}{ HOTS } & \multirow[b]{2}{*}{ SCE } & \multicolumn{2}{|c|}{ Component } & \multirow[b]{2}{*}{$\mathrm{D}$} \\
\hline & & & & QoR & WC & \\
\hline writemor & & & & & .707 & \\
\hline writemid & & & & & .847 & \\
\hline writesml & & & & & .794 & \\
\hline analyze & & .841 & & & & \\
\hline synthesz & & .849 & & & & \\
\hline evaluate & & .769 & & & & \\
\hline applying & & .774 & & & & \\
\hline clquest & .492 & & -.296 & .222 & & \\
\hline facgrade & .453 & & & & & .245 \\
\hline facplans & 699 & & & & & \\
\hline facideas & .720 & & & & & \\
\hline facother & .784 & & & & & \\
\hline resrch04 & .709 & & & & & \\
\hline divrstud & & & & & & .938 \\
\hline diffstu2 & & & & & & .909 \\
\hline envdivrs & & & .805 & & & \\
\hline envsocal & & & .819 & & & \\
\hline envsuprt & & & .535 & .300 & & \\
\hline
\end{tabular}




\begin{tabular}{|c|c|c|}
\hline envnacad & & .785 \\
\hline envstu & & \\
\hline envfac & .251 & \\
\hline
\end{tabular}

\begin{tabular}{lllllll}
\hline \% of variance & $26.01 \%$ & $9.86 \%$ & $8.10 \%$ & $7.25 \%$ & $5.71 \%$ & $4.96 \%$
\end{tabular}

Explained

Note. Factor loadings $<.2$ are suppressed. Bold numbers indicate primary factor loading. $\quad$ SFI $=$ Student-Faculty Interaction; HOTS $=$ Higher-Order Thinking Skill; $\mathrm{SCE}=$ Supportive Campus Environment; $\mathrm{QoR}=$ Quality of Relationship; $\mathrm{WC}=$ Writing Challenge; $\mathrm{D}=$ Diversity.

\subsection{Results of Confirmatory Factor Analysis of Six-factor Model}

With this new model, a CFA was conducted on the 2011 seniors' data to validate this new test blueprint. Table 4 presents the results of the CFA, including the factor loadings for each of the items. As shown, the overall reliability was .827 , with strong reliabilities on all of the scales: writing challenge (.616), higher-order thinking skills (.779), student-faculty interaction (.715), diversity (.822), supportive campus environment (.807), and quality of relationships (.683).

Table 4. Benchmarks and Item loadings for the Revised NSSE Six-Benchmark Model With the 2011 Senior Sample $(\mathrm{n}=655)$

Benchmark Measure Loading Benchmark Reliability

Items

Original Instrument (Overall scale) .827

Writing Challenge

WRITEMOR .443

WRITEMID

.966

WRITESML

.496

Higher-Order Thinking Skill

ANALYZE

YNTHESZ

.829

VALUATE

.659

APPLYING

.615

Student-Faculty Interaction

CLQUEST

FACGRADE

FACPLANS

FACIDEAS

FACOTHER

Diversity

DIVRSTUD

DIFFSTU2 
ENVSOCAL

ENVSUPRT

ENVACAD

Quality of Relationships

ENVSTU

ENVFAC

ENVADM
.719

.640

.792

.683

Table 5 presents the model fit indices of this CFA. As shown, there was a good model-data fit between the new model and the 2011 seniors' data. In addition to other strong fit indices, the RMSEA of .038 is less than our threshold, indicating a good fit, with the CFit of 1.0 indicating a strong probability that the RMSEA is less than or equal to 0.05 (see Brown, 2006).

Table 5. Fit Indices for the Revised Model With the 2011 Senior Sample

\begin{tabular}{cccccc}
\hline Cohort & CFI & TLI & RMSEA & CFit & SRMR \\
\hline Seniors & .953 & .944 & .038 & 1.00 & .037
\end{tabular}

Table 6 summarizes the differences in how items load on each factor in each of the models. For example, ACADPR01 was a variable included in the original five-factor NSSE model and was proposed to load on Level of Academic Challenge. However, in the revised six-factor model, this variable did not load on any of the factors. ANALYZE was another variables included in the Level of Academic Challenge scale on the original model; however, on the revised model, it loaded on the Higher Order Thinking Skills factor.

Table 6. Comparison of factor loadings - Original NSSE Model and Revised Model

\begin{tabular}{lll}
\hline \multicolumn{1}{c}{ Item } & \multicolumn{1}{c}{ Original model factor } & \multicolumn{1}{c}{ Revised model factor } \\
\hline ACADPR01 & Level of Academic Challenge & --- \\
ANALYZE & Level of Academic Challenge & HO Thinking Skills \\
APPLYING & Level of Academic Challenge & HO Thinking Skills \\
ENVSCHOL & Level of Academic Challenge & --- \\
EVALUATE & Level of Academic Challenge & HO Thinking Skills \\
READASGN & Level of Academic Challenge & --- \\
SYNTHESZ & Level of Academic Challenge & HO Thinking Skills \\
WORKHARD & Level of Academic Challenge & --- \\
WRITEMID & Level of Academic Challenge & Writing Challenge \\
WRITEMOR & Level of Academic Challenge & Writing Challenge \\
WRITESML & Level of Academic Challenge & Writing Challenge \\
& & \\
CLASSGRP & Active \& Collaborative Learning & --- \\
COMMPROJ & Active \& Collaborative Learning & --- \\
CLPRESEN & Active \& Collaborative Learning & --- \\
CLQUEST & Active \& Collaborative Learning & Student-Faculty Interaction \\
OCCIDEAS & Active \& Collaborative Learning & --- \\
OCCGRP & Active \& Collaborative Learning & --- \\
TUTOR & Active \& Collaborative Learning & ---
\end{tabular}




\begin{tabular}{|c|c|c|}
\hline FACFEED & Student-Faculty Interaction & --- \\
\hline FACGRADE & Student-Faculty Interaction & Student-Faculty Interaction \\
\hline FACIDEAS & Student-Faculty Interaction & Student-Faculty Interaction \\
\hline FACPLANS & Student-Faculty Interaction & Student-Faculty Interaction \\
\hline FACOTHER & Student-Faculty Interaction & Student-Faculty Interaction \\
\hline RESRCH04 & Student-Faculty Interaction & Student-Faculty Interaction \\
\hline COCURR01 & Enriching Educ Experiences & --- \\
\hline DIFFSTU2 & Enriching Educ Experiences & Diversity \\
\hline DIVRSTUD & Enriching Educ Experiences & Diversity \\
\hline ENVDIVRS & Enriching Educ Experiences & Supportive Campus Environment \\
\hline FORLNG04 & Enriching Educ Experiences & --- \\
\hline INDSTD04 & Enriching Educ Experiences & --- \\
\hline INTERN04 & Enriching Educ Experiences & --- \\
\hline ITACADEM & Enriching Educ Experiences & --- \\
\hline LRNCOM04 & Enriching Educ Experiences & --- \\
\hline SNRX04 & Enriching Educ Experiences & --- \\
\hline STDABR04 & Enriching Educ Experiences & --- \\
\hline VOLNTR04 & Enriching Educ Experiences & --- \\
\hline ENVACAD & Supportive Campus Environ & Supportive Campus Environment \\
\hline ENVADM & Supportive Campus Environ & Quality of Relationships \\
\hline ENVFAC & Supportive Campus Environ & Quality of Relationships \\
\hline ENVSOCAL & Supportive Campus Environ & Supportive Campus Environment \\
\hline ENVSUPRT & Supportive Campus Environ & Supportive Campus Environment \\
\hline ENVSTU & Supportive Campus Environ & Quality of Relationships \\
\hline
\end{tabular}

Note: Refer to the College Student Report NSSE 2008 and 2011 Codebook for the actual questions (www.nsse.iub.edu/).

\section{Discussion and Conclusion}

The National Survey of Student Engagement (NSSE) was created to determine the degree to which postsecondary students engage in meaningful educational practices that will enhance their educational outcomes. NSSE provides summative information on five scales that can be used to compare institutions or cohorts within institutions. The use of NSSE has increased dramatically among U.S. colleges and universities and is now an important component of the Voluntary System of Accountability, enhancing the potential high stakes use of this instrument. Because other studies have noted that the NSSE may not be appropriate to measure engagement at a particular institution, this study was conducted to examine how well the five-factor NSSE model fit the 2008 seniors' data from a research intensive institution. As has been found by others within their own institutional contexts (i.e., Campbell \& Cabrera, 2011; Gordon, Ludlum, \& Hoey, 2008; LaNasa et al., 2009), the results of a Confirmatory Factor Analysis indicated that the model did not fit the data at our institution. Consequently, an alternative model was developed by conducting an exploratory factor analysis on the 2008 data that resulted in a six-factor structure. This revised model was then used in a CFA to test its fit with the 2011 seniors' data at the same institution. These results indicated that the new model fit the data better than the original five-factor NSSE model.

Table 6 provides a comparison of how each of the original 42 items were intended to load on the original five factors of the NSSE model and how they loaded on the revised six-factor model. Some items loaded on the similarly titled factor in each model. For instance, FACGRADE and FACIDEAS both loaded on factors labeled "Student-faculty interaction," Other items, such as DIFFSTU2 and DIVERSTUD, loaded on the original NSSE 
factor labeled "Enriching educational experiences." In our six-factor model, these two variables loaded on a more specific aspect of those experiences: "Diversity." Similarly, ANALYZE and APPLYING loaded on the original NSSE factor of "Level of Academic Challenge." In our model, these items loaded on "Higher Order Thinking Skills."

In their study at an urban university of first-year students' data, LaNasa et al. (2009) found a model with eight factors best fit those students. This eight-factor structure differs from our six-factor structure derived from seniors' data. Though there are similarities between the models in the two studies, the focus of each of our six factors was different and so was differently labeled. For instance, "learning strategies," one of the LaNasa et al., factors, had four items from the original NSSE factor labeled "Level of Academic Challenge:" (1) synthesize; (2) analyze; (3) evaluate; and (4) applying. In our study a similar factor was labeled "higher-order thinking skills." Likewise, they have a factor labeled "institutional emphasis" and the four items that measure that factor were part of the "supportive campus environment" factor in our study. Both models - ours and the one developed by LaNasa et al. - provided more focused factors (e.g., "learning strategies" or "higher-order thinking skills") than the more generic factors (e.g., "level of academic challenge") of NSSE. Differences in our model and that of LaNasa et al. may be due to the missions of the different universities - theirs being urban and research-intensive, while ours is a public, land-grant, research-intensive university (that is also located in a more semi-rural area). Differences might also be due to their use of first-year students and our use of senior students. We posit that the information collected by the NSSE instrument should be primarily of use to institutional stakeholders and when there are commonalities across institutions then comparisons may be fruitful. However, it is important to consider differences in student bodies. For example, though NSSE is administered to both freshman cohorts and senior cohorts at each institution, we chose to examine only the senior group at our university, assuming that levels and types of engagement would be significantly different between those two groups. In fact, in preliminary comparisons between these two groups, seniors, as would be expected, had higher mean scores, indicating higher engagement levels, than first-year students. It may be that some institutions may wish to develop or test a model of engagement using freshman data as a way to present formative evaluations of the college experience - addressing potential changes that might be indicated through the freshman data to enhance engagement as student proceed through the system to their graduating year.

Influencing decision making is one of the hardest challenges in assessment (Pike, 2002). Pike underlined the importance of practical decisions that could be made based on the assessment results. In this study, based on the strong model-data fit that was obtained, it is possible to conclude that this university should place special emphasis on the six factors-student-faculty interaction, higher-order thinking skill, supportive campus environment, quality of relationship, writing challenge, and diversity - as a way to examine student engagement at the institution. Doing so may positively impact student engagement and their educational experiences at this institution.

\section{Limitations}

The scope of this study was limited to data from one institution and from only the senior group of students at that institution responding to the NSSE. Response rates to the survey were typical of response rates at other institutions but still low (below 35\%), with no follow-up of no respondents to examine potential sources of response bias. Processes and perceptions of student engagement may be different from institution to institution, a finding suggested by the results of this study. Engagement may also vary between seniors and freshmen at any institution.

In order to strengthen the findings of this study, it would be helpful to have similar studies replicated at other colleges and universities that participated in the NSSE survey. Unlike Swerdzewski et al. (2007), Lutz and Culver (2010), and Campbell and Cabrera (2011), studies at the individual institution level should go beyond determining whether or not the five-factor model fits their data by proceeding to develop an alternate set of factor structures that may better represent their data. Such replication studies can contribute to the overall discussion and improvement of the NSSE survey so that meaningful interpretations and comparison among schools can be drawn from the NSSE data.

\section{References}

Astin, A. W. (1984). Student involvement: A developmental theory for higher education. Journal of College Student Personnel, 25, 297-307.

Astin, A. W. (1993). What matters in college? Four critical years revisited. San Francisco, CA: Jossey-Bass. 
Astin, A. W., \& Sax, L, J. (1998). How undergraduates are affect by service participation. The Journal of College Student Development, 39(3), 251-263.

Brown, T. A. (2006). Confirmatory factor analysis for applied research. New York, NY: Guilford.

Bruffee, K. A. (1993). Collaborative learning: Higher education, interdependence, and the authority of knowledge. Baltimore, MD: Johns Hopkins University Press.

Campbell, C. M., \& Cabrera, A, F. (2011). How sound is NSSE? Investigating the psychometric properties of NSSE at a public, research-extensive institution. The Review of Higher Education, 35(1), 77-103. http://dx.doi.org/10.1353/rhe.2011.0035

Chickering, A. W., \& Gamson, Z. F. (1987). Seven principles for good practice in undergraduate education. AAHE Bulletin, 39(7), 3-7.

Goodsell, A., Maher, M., \& Tinto, E. (Eds.). (1992). Collaborative learning: A sourcebook for higher education.

University Park, PA: National Center on Postsecondary Teaching, Learning and Assessment, The Pennsylvania State University.

Gordon, J., Ludlum, J., \& Hoey, J. J. (2008). Validating NSSE against student outcomes: Are they related? Research in Higher Education, 49, 19-39. http://dx.doi.org/10.1007/s11162-007-9061-8

Harper, S. R. (2009). Race-conscious student engagement practices and the equitable distribution of enriching educational experiences. Liberal Education, 95(4), 38-45.

Hu, L., \& Bentler, P.M. (1999). Cutoff criteria for fit indexes in covariance structure analysis: Conventional criteria versus new alternatives. Structural Equation Modeling, 6, 1-55. http://dx.doi.org/10.1080/10705519909540118

Jones, R. D. (2009). Student engagement teacher handbook. Rexford, NY: International Center for Leadership in Education.

Kuh, G. D. (2003). The National Survey of Student Engagement: Conceptual framework and overview of psychometric properties. Retrieved from http://nsse.iub.edu/pdf/conceptual_framework_2003.pdf

Kuh, G. D. (2009). The national survey of student engagement: Conceptual and empirical foundations. New Directions for Institutional Research, 2009, 5-20. http://dx.doi.org/10.1002/ir.283

Kuh, G. D., Kinzie, J.,Schuh, J. S., Whitt, E. J., \& Associates. (2005). Student success in college: Creating conditions that matter. San Francisco, CA: Jossey-Bass.

LaNasa, S., Cabrera, A. F., \& Trangsrud, H. (2009). The construct validity of student engagement: A confirmatory factor analysis. Research in Higher Education, 50, 313-352. http://dx.doi.org/10.1007/s11162-009-9123-1

Lutz, M. E., \& Culver, S. (2010). The National Survey of Student Engagement: A university-level analysis. Tertiary Education and Management, 16(1), 35-44. http://dx.doi.org/10.1080/13583881003629814

McKeachie, W. J., Pintrich, P. R., Lin, Y., \& Smith, D. (1986). Teaching and learning in the college classroom: A review of the research literature. Ann Arbor, MI: National Center for Research to Improve Postsecondary Teaching and Learning, University of Michigan.

Meyers, L. S., Gamst, G., \& Guarino, A.J. (2006). Appliedmultivariate research: Design and interpretation. Thousand Oaks, CA: Sage.

Muthen, B., \& Muthen, L. (2008). Mplus User's Guide. Los Angeles, CA: Muthen and Muthen.

NSSE. (2008). Promoting engagement for all students: The imperative to look within. Bloomington, IN: Indiana University Center for Postsecondary Research. http://nsse.iub.edu/NSSE_2008_Results/docs/withhold/NSSE2008_Results.pdf

NSSE. (2011). A guide to your NSSE institutional report 2011. Bloomington, IN: Indiana University Center for Postsecondary Research.http://nsse.iub.edu/2011_Institutional_Report/pdf/NSSE_Guide_2011.pdf

Pascarella, E. T., \& Terenzini, P. T. (1991). How college affects students: Findings and insights from twenty years of research. San Francisco, CA: Jossey-Bass.

Pascarella, E. T., \& Terenzini, P. T. (2005). How college affects students: Vol. 2. San Francisco, CA: Jossey-Bass. 
Pike, G. R. (2002). Measurement issues in outcomes assessment. In T. Banta (Ed.), Building a scholarship assessment (pp. 131-147). San Francisco, CA: Jossey-Bass.

Pike, G. R. (2006). The dependability of NSSE scalelets for college- and department-level assessment. Research in Higher Education, 47(2), 177-195. http://dx.doi.org/10.1007/s11162-005-8885-3

Pike, G. R., \& Kuh, G. D. (2005). A typology of student engagement for American colleges and universities. Research in Higher Education, 46(2), 185-209. http://dx.doi.org/10.1007/s11162-004-1599-0

Pike, G. R., Kuh, G. D., \& Gonyea, R. M. (2003). The relationship between institutional mission and students' involvement and educational outcomes. Research in Higher Education, 44, 2, 241- 261.

Pike, G. R., Kuh, G. D., McCormick, A. C., Ethington, C. A., \& Smart, J. C. (2011). If and when money matters: The relationships among educational expenditures, student engagement, and students' learning outcome. Research in Higher Education, 52(1), 81-106. http://dx.doi.org/10.1007/s11162-010-9183-2

Smart, J. C., Feldman, K. A., \& Ethington, C. A. (2000). Academic disciplines: Holland's theory and the study of college students and faculty. Nashville, TN: Vanderbilt University Press.

Swerdzewski, P., Miller, B. J., \& Mitchell, R. (2007, October). Investigating the validity of the National Survey of Student Engagement. Paper presented at the meeting of the Northeastern Educational Research Association, Rocky Hill,

CT. http://www.learningace.com/doc/3131545/6213edae04f1b00b43792d1c1681c99b/swerdzewskimillermitche llnera

Tinto, V. (1997). Classrooms as communities: Exploring the educational character of student persistence. Journal of Higher Education, 68(6), 599-623.

Yarbrough, D. B., Shulha, L. M., Hopson, R. K., \& Caruthers, F. A. (2011). The program evaluation standards: A guide for evaluators and evaluation users. ( $3^{\text {rd }}$ ed.). ThousandOaks, CA: Sage.

Yu, C.Y. (2002). Evaluating cutoff criteria of model fit indices for latent variable models with binary and continuous outcomes. Unpublished doctoral dissertation, University of California, Los Angeles.

\section{(cc) $\mathbf{E Y}$}

This work is licensed under a Creative Commons Attribution 3.0 License. 